\title{
Sensory and Textural Evaluation of Gluten-Free Bread Substituted With Amaranth and Montina ${ }^{\mathrm{TM}}$ Flour
}

\author{
Karen L. Breshears ${ }^{1} \&$ Kristi M. Crowe ${ }^{2}$ \\ ${ }^{1}$ Department of Nutrition and Kinesiology, University of Central Missouri, Warrensburg, Missouri, USA \\ ${ }^{2}$ Department of Human Nutrition, University of Alabama, Tuscaloosa, Alabama, USA \\ Correspondence: Karen L. Breshears, Department of Nutrition and Kinesiology, University of Central Missouri, \\ Warrensburg, MO 64093, USA. Tel: 1-660-543-8737. E-mail: kbreshears@ucmo.edu
}

\author{
Received: December 3, 2012 Accepted: June 3, 2013 Online Published: June 17, 2013 \\ doi:10.5539/jfr.v2n4p1 \\ URL: http://dx.doi.org/10.5539/jfr.v2n4p1
}

\begin{abstract}
The objective of this study was to develop a nutrient-dense gluten-free bread (GFB) using either amaranth or Montina $^{\mathrm{TM}}$ flour in a standardized gluten-free lean bread recipe for the purpose of comparing the nutritional, sensory, and objective qualities of the developed breads to a commercially-marketed GFB. Participants $(n=222)$ included individuals who typically eat a gluten-free diet and those who eat a non-restricted diet. The non-restricted diet group was used to assess product acceptability in the general population and to determine product marketability among those without gluten restrictions. Nutritionally, both developed breads provided at least $26 \%$ more iron than the commercial GFB and $\geq 40 \%$ more fiber while the amaranth bread provided twice as much folate. Significant differences $(p<0.05)$ in sensory attributes (appearance, texture, flavor, tenderness, and overall acceptability) of both amaranth- and Montina ${ }^{\text {TM}}$-based breads were not reported between the groups. Based on sensory scores using a 9-point Hedonic scale, the commercial GFB was preferred over either developed bread and the Montina ${ }^{\text {TM}}$-based bread was preferred over the amaranth-based bread. Significant differences in bread hardness were not detected among the tested GFB, yet commercial GFB slices exhibited the largest and most consistent cell size throughout. Results suggest that amaranth and Montina ${ }^{\mathrm{TM}}$ flours assist in improving the nutritional quality of GFB, yet additional testing is needed to assist in formulation modifications of this standardized lean bread recipe in order to produce a product similar in sensory qualities to commercially-marketed GFB.
\end{abstract}

Keywords: sensory evaluation, gluten-free bread, amaranth, Montina ${ }^{\mathrm{TM}}$

\section{Introduction}

Celiac Disease (CD), an autoimmune response to foods containing gluten, presents itself in genetically-susceptible individuals resulting in lesions or total flattening of intestinal villi (Garcia-Manzanares \& Lucendo, 2011; See \& Murry, 2006). Currently, this disease affects one in 100 individuals worldwide or 1-2\% of the general population, although not all have symptoms or are diagnosed with the disease. At present, the only treatment for $\mathrm{CD}$ is strict adherence to a gluten-free diet (GFD), which means abstaining from products containing offending proteins within wheat, rye, barely, spelt, and, in some cases, oats that were contaminated during processing (Alvarez-Jubete, Arendt, \& Gallagher, 2009; de la Barca, Rojas-Martinex, Islas-Ruboi, \& Cabrera-Chávez, 2010; Garcia-Manzanares \& Lucendo, 2011; See \& Murry, 2006). However, those with CD are not the only individuals who require a GFD. Gluten intolerant (GI) individuals have similar sensitivities to gluten including many of the same symptoms, and thus, must follow a GFD. According to current statistics, GI is 30 times more widespread than CD ("What is gluten intolerance", n.d.).

Among the gluten-free offerings on the market, gluten-free yeast bread (GFB) products are not known for their outstanding taste, texture or nutrient density. Likewise, giving up yeast bread is often difficult for those with CD or those who are GI because yeast bread products are a staple in the typical American diet (Anton \& Artfield, 2008). As such, elimination of breads, pasta, and pastries containing the protein fractions that comprise gluten can be a challenge for those on a GFD. Another concern for individuals adhering to a GFD is the availability of GFB products. Not all grocery stores carry GF items, and thus, products must be purchased at specialty stores or on the Internet. Furthermore, the availability of GF products varies across the United States (US) with coastal cities having the greatest variety while the Midwest has more limited choices (Lee, Ng, Zivin, \& Green, 2007; 
Singh \& Whelan, 2011).Collectively, these factors can lead to low dietary compliance rates which are currently between $50-80 \%$ (Garcia-Manzanares \& Lucendo, 2011), and as a result, those with CD or who are GI may be at risk for a host of nutrient deficiencies.

The GFD calls for the elimination of offending culprits, which are the protein fractions that comprise gluten: gliadin and glutenin. These proteins require hydration and manipulation in doughs and batters to form gluten which is responsible for contributing plasticity and elasticity to breads. Gluten development is critical to the finished texture of breads because of its ability to trap expanding gases during the rising and baking processes (Anton \& Artfield, 2008; Arendt \& Moore, 2006; Arendt, Renzetti, \& Bello, 2009). Overall, gluten impacts the cell size and formation, crumb structure (Without gluten, bread is dry and crumbly.), volume, and airiness of baked goods to the extent that products made with non-gluten forming flours often have poor textural quality and mouthfeel along with a pasty flavor or aftertaste (Anton \& Artfield, 2008; Arendt \& Moore, 2006). As a culinary guideline, when substituting GF flours in baked goods, alterations to the recipe must be made in order to create an acceptable, aesthetically-pleasing product. In order to achieve these sensory goals, recipes need to include a polysaccharide- or protein-based hydrocolloid that forms a gel with water and mimics the properties of gluten in the final product. Examples of hydrocolloids commonly used in baking applications include guar gum, xanthan gum, or methylcellulose and either whey or egg albumin all which provide elasticity and desired textural qualities (Abdel-Aal, 2009; Anton \& Artfield, 2008; Arendt et al., 2009).

Among the most common ingredients used in GFB products are rice starch, cornstarch, potato starch, and/or tapioca starch (Arendt et al., 2009; Pagano, 2006). These non-wheat starches have been used in many cultures for generations, and as a result, these starches have met with success among product formulations sold in the GF marketplace. Additional wheat-alternative grains are available on the market some of which are more nutritious than wheat. For example, amaranth, Indian rice grass (Montina ${ }^{\mathrm{TM}}$ ), millet, quinoa, sorghum, Timothy grass seed (Timtana $\AA$ ), and bean flours such as navy bean or garbanzo bean are among the more commonly used GF flours. Among these, amaranth is higher than wheat in protein, fiber, iron, calcium, magnesium, and zinc (Pagano, 2006; "USDA National Nutrient Database", 2010). Likewise, Montina ${ }^{\mathrm{TM}}$, which was a dietary staple of Native Americans prior to the introduction of maize (Barr, 2004), is higher in protein, fiber, iron, and calcium than wheat ("Mission Mountain Food Enterprise Center", n.d.; Sands, 2010). Although there is little experimental research published on the bread-making qualities of Montina ${ }^{\mathrm{TM}}$, it is known in the culinary realm to impart good textural qualities to GFB products with acceptable substitution levels of $10-30 \%$ of the total flour (Hillson, 2010; Gruss, n.d.). However, since none of the alternative grains have the exact baking qualities of wheat, a blend of flours is typically needed to attain an acceptable product.

While the nutritional quality of some GF flours may be nutritionally superior to wheat, some GFB products are nutritionally inferior to their counterparts made with wheat. This is partially due to the fact that wheat flour, by law, is enriched during the milling process in order to enhance the nutritional quality. Because the vast majority of GF flours are not enriched or fortified, products made with these ingredients are often lower in nutritional quality (Thompson, 2000, 2009). For example, GFB products have been reported to have a lower thiamin, riboflavin, niacin, iron and, sometimes, fiber content (Thompson, 2000). Thus, the nutritional quality of GFB products must be carefully considered during the development phase. Lastly, it is also important to consider that iron, folate, fiber, calcium, and vitamins $\mathrm{D}, \mathrm{B}_{12}$ and $\mathrm{B}_{6}$ are all nutrients that those with $\mathrm{CD}$ are commonly deficient in upon initial diagnosis (Garcia-Manzanares \& Lucendo, 2011; Hallert et al., 2002; Saturni, Ferretti, \& Baccheeti, 2010; See \& Murry, 2006). Although some of these vitamin and mineral deficiencies correct themselves as a result of strict adherence to a GFD, many nutrient deficiencies still remain due to inadequate dietary intake or poor compliance (Garcia-Manzanares \& Lucendo, 2011; Kinsey, Burden \& Bannerman, 2008; Thompson, Dennis, Higgins, Lees, \& Sharrett, 2005). For these reasons, the sensory qualities are not the only considerations that should be taken into consideration during the development of GFB products.

As the GF retail market continues to grow at a rapid rate, the use of GFB products varies among the GF population (Arendt \& Moore, 2006), yet numerous studies have documented the frequency of GFB as a staple in the diet of individuals with CD (Araújo \& Araújo, 2011; Black \& Orfila, 2011; Gilbert et al., 2006; Lamontagne, West \& Galibois, 2001). Taken collectively, these studies show that GFB is consumed frequently and is important in assisting with dietary compliance by those who follow a GFD. Therefore, substituting alternative grains with higher nutrient density than those commonly used in commercial products may be beneficial for GF consumers, especially those who wish to consume a nutritious GFD without depending on commercial products. For these reasons, the objective of this study was to develop a nutrient-dense GFB prepared from a standardized consumer recipe for the purpose of comparing the nutritional, sensory, and objective qualities of the developed 
bread to a commercially-marketed GFB product. After a pilot study to evaluate preferences and substitution levels, amaranth and Montina ${ }^{\mathrm{TM}}$ flour were chosen as the nutrient-dense starches for this study.

\section{Methods}

\subsection{Development of Bread}

A standardized lean bread recipe (Coppedge, 2008) was used to develop GFB with amaranth or Montina ${ }^{\mathrm{TM}}$ flour. Based on the results of the pilot study, amaranth and Montina ${ }^{\mathrm{TM}}$ were substituted at a percentage of the total starch by weight to achieve product acceptability. The final level of substitution for the amaranth and Montina ${ }^{\mathrm{TM}}$ flour was $20 \%(70 \mathrm{~g})$ of total flour weight. Table 1 lists the ingredients and preparation procedures. A commercial GFB product served as the comparison product for this study in order to establish a comparison for consumer expectations for sensory and quality attributes of GFB.

Table 1. Recipe ingredients and preparation procedures ${ }^{\mathrm{a}}$ of developed gluten-free bread

\begin{tabular}{ll}
\hline White Rice Flour & $95 \mathrm{~g}$ \\
\hline Potato Starch & $95 \mathrm{~g}$ \\
Tapioca Starch & $50 \mathrm{~g}$ \\
Soy Flour & $50 \mathrm{~g}$ \\
Amaranth or Montina ${ }^{\mathrm{TM}}$ Flour & $70 \mathrm{~g}$ \\
Whey & $10 \mathrm{~g}$ \\
Guar Gum & $25 \mathrm{~g}$ \\
Dry Egg White Powder & $30 \mathrm{~g}$ \\
Salt & $9 \mathrm{~g}$ \\
Instant Yeast & $12 \mathrm{~g}$ \\
Liquid Egg Whites & $100 \mathrm{~g}$ \\
Carbonated Water & $385 \mathrm{~g}$ \\
\hline
\end{tabular}

${ }^{\mathrm{a}}$ Procedure for preparing GFB with partial flour replacement using amaranth or Montina ${ }^{\mathrm{TM}}$ flour - Prepared in a non-contaminated kitchen with utensils and ingredients which were known to be GF. Each ingredient was weighed and mixed in a Kitchen Aid Mixer (Model KS25GOX, Kitchen Aid USA, Greenville, OH) equipped with a paddle on Speed 2 for a total of 4 min. Dough was placed in $9 \times 5(23 \times 13 \mathrm{~cm})$ bread pans lined with parchment paper, allowed a rise time of $30 \mathrm{~min}$ in a warming tray, and baked for $50 \mathrm{~min}$ at $375^{\circ} \mathrm{F}\left(190^{\circ} \mathrm{C}\right)$ to an internal temperature of at least $210^{\circ} \mathrm{F}\left(100^{\circ} \mathrm{C}\right)$. Breads were immediately removed from pan and cooled completely on a wire rack prior to testing.

\subsection{Nutritional Composition}

Nutrient composition for the three breads evaluated in sensory analysis was determined using Official Methods of Analysis of the Association of Official Analytical Chemists (AOAC) for crude protein by the Kjeldahl method, crude fat, crude fiber, iron, calcium, folate, and vitamin $\mathrm{B}_{12}$ (Latimer, 2012). Carbohydrates were determined by difference method. Proximate analysis and mineral analyses were performed by the Agricultural Experiment Station Chemical Laboratories at the University of Missouri-Columbia and vitamin analysis was performed by Silliker, Inc.

\subsection{Sensory Evaluation of Developed Breads}

Two hundred and twenty-two untrained volunteers (58 males and 164 females ages 19 to 85 ) recruited from faculty, staff, and students at a university and three Celiac support groups in the Midwestern US participated in sensory analysis. Among these, 44.6\% were between 19 and 24; $9 \%$ between $25-34 ; 6.3 \%$ between $35-44 ; 15.8 \%$ between $45-54 ; 10.8 \%$ between $55-64$; and $13.5 \%$ over age 65 . Participants recruited for the study included individuals who typically eat a GF diet and those who eat a non-restricted diet. The non-restricted diet group was used to assess product acceptability in the general population and to determine product marketability among those without gluten restrictions. Ninety-two participants reported eating GF products at least 2-3 times per week and were grouped as GF consumers. The remaining 129 were grouped in the non-restricted diet group because 
they did not eat gluten-free products. Power calculations revealed 92 participants per group were necessary for statistical significance in comparing groups. The study was approved by the Institutional Review Board of the partnering institution and panelists signed consent forms per human subjects protocol.

Sensory analysis was conducted according to guidelines by Larmond (1991), Lawless and Heymann (2010, Chapter 14) and Stone and Sidel (2004) using a 9-point Hedonic scale ranging from like extremely to dislike extremely to assess appearance, texture, flavor, tenderness, and overall acceptability. A five-point Hedonic scale was used to assess usage and marketability. To control variability, panelists were seated at individual booths at which randomly coded and presented samples were provided on disposable white plates. After the products were tested, the unconsumed product and plate were removed prior to the next product presentation. In accordance with standard sensory testing procedures, panelists cleansed their palettes between samples with filtered tap water $\left(25^{\circ} \mathrm{C}\right)$.

\subsection{Objective Measures}

Developed breads were compared to the commercial GFB product to assess differences in texture, cell size, and cell uniformity. Texture analysis was completed on a Brookfield LFRA-100 Texture Analyzer (Brookfield Engineering Laboratories, Middleboro, MA). A TA 4/1000 cylinder probe (38.1 mm diameter, $20 \mathrm{~mm}$ length, AOAC Standard) was used to measure hardness of the bread by measuring force in compression on a $1.75 \mathrm{~cm}$ slice of bread (Mezaize, Chevallier, Le Bail, \& De Lamballerie, 2009; Krupa, Rosell, Sadowska, \&Soral-Smietana, 2010). Hardness was defined as the maximum force in grams at peak load measured at velocity of $0.5 \mathrm{~mm} / \mathrm{s}$ (Hoye \& Ross, 2011). Texture analysis was performed in triplicate for each bread type. Uniformity and cell size of the bread were measured using a flatbed scanner at 350 dpi according to standard procedures (de la Barca et al., 2010; McWilliams, 2008; Schober, Bean, \& Boyle, 2007; Yano, 2010).

\subsection{Statistical Methods}

Group difference toward bread preferences and bread textures were analyzed for statistical significance $(p<0.05)$ with repeated measures ANOVA and Tukey's HSD post hoc testing using SPSS Statistics 19 (2010, IBM Company).

\section{Results and Discussion}

\subsection{Nutritional Comparison}

Compared to the commercial product, the developed GFB products had nutritional advantages for total carbohydrate provision along with iron, fiber, and folate content (Table 2). The energy content of the commercial GFB product was higher than either developed GFB likely due to added sugars and/or fat. For example, the commercial GFB had twice as many carbohydrates per $100 \mathrm{~g}$ than either developed GFB. This could be significant for glycemic control if managing a diabetic diet along with a GFD. Both CD and Type 1 Diabetes are autoimmune diseases which occur together in $3.9-12.3 \%$ of all CD cases ("Do You Have Celiac Disease", n.d.). Both developed breads contained 52-60\% less calcium than the commercial product, and were similarly lower in calcium than most commercial wheat breads ("Arnold Bread", 2012; "Nature's Own", 2012). The iron content of amaranth and Montina ${ }^{\mathrm{TM}}$ breads was $45 \%$ and $26 \%$ higher, respectively, than the iron content in the commercial product. Additionally, the fiber content of the bread developed with Montina ${ }^{\mathrm{TM}}$ flour was $59 \%$ higher than the commercial GFB product whereas the amaranth-based bread provided approximately $40 \%$ more fiber than the commercial GFB product. The vitamin $\mathrm{B}_{12}$ content was two to three times higher in the commercial bread than in the amaranth and Montina ${ }^{\mathrm{TM}}$ - based breads. Although none of the products were significant sources of vitamin $\mathrm{B}_{12}$, each would contribute less than $5 \%$ to the overall dietary intake ("Dietary Supplement Fact Sheet: Vitamin $\left.\mathrm{B}_{12}, 2011\right)$. The folate content was $50 \%$ higher in the amaranth bread compared to the commercial product, whereas Montina $^{\mathrm{TM}}$ was $8 \%$ lower in folate than the commercial product. Since a food is considered a good source of folate if it contains $10 \%$ of the recommended daily amount ("Folate Fact Sheet", 2004), one serving of the amaranth-based bread would be considered a good source of folate (16\% of Daily Value). Nevertheless, since iron, fiber, vitamin $\mathrm{B}_{12}$, and folate are four of the nutrients commonly deficient among newly diagnosed individuals, the breads developed with these nutritious alternative GF flours may assist in providing these critical nutrients. 
Table 2. Nutrient composition $^{\mathrm{a}}$ of developed gluten-free breads as compared to a commercially-marketed gluten-free bread

\begin{tabular}{llll}
\hline Per $100 \mathrm{~g}$ & Amaranth & Montina $^{\mathrm{TM}}$ & Commercial \\
\hline Energy (kcal) & 214.28 & 192.2 & 351.16 \\
Crude Fat $(\mathrm{g})$ & 5.04 & 0.64 & 5.52 \\
Carbohydrate $(\mathrm{g})$ & 31.86 & 36.52 & 65.1 \\
Crude Protein $(\mathrm{g})$ & 10.37 & 10.09 & 10.27 \\
Crude Fiber $(\mathrm{g})$ & 0.74 & 1.07 & 0.44 \\
Calcium (mg) & 46.7 & 38.7 & 96.8 \\
Iron $(\mathrm{mg})$ & 1.71 & 1.29 & 0.95 \\
$\mathrm{~B}_{12}(\mathrm{mcg})^{\mathrm{b}}$ & 0.14 & 0.12 & 0.36 \\
Folate $^{(\mathrm{mcg})}$ & 65.7 & 34.1 & 37.8 \\
\hline
\end{tabular}

${ }^{\text {a }}$ Proximate, mineral, and vitamin analyses performed according to approved AOAC methods.

\subsection{Sensory Evaluation}

The research population is similar to those with $\mathrm{CD}$, as up to $70 \%$ of those diagnosed with $\mathrm{CD}$ are women (Green \& Cellier, 2007; Shah \& Leffler, 2010), and although CD can occur in any ethnicity, it is most common in those from European decent (See \& Murry, 2006). Published data on GI demographics is not yet available, so comparisons with this population are yet to be determined (Di Sabatino \& Corazza, 2012); however, the demographics are considered to be similar to the CD population as a whole. As such, the finding of this study may be generalized to the $\mathrm{CD}$ population.

There were no statistically significant differences $(p>0.05)$ between participant groups in overall acceptance of the two developed GFB products suggesting that the developed breads were equally acceptable to both participant groups (results not shown). Using a 9-point Hedonic scale, the mean acceptance scores for the GF/ non-restricted groups were 5.8/5.9 for amaranth and 6.5/6.2 for Montina ${ }^{\mathrm{TM}}$. In agreeance with these study results, Zandonadi, Botelho and Araújo (2009) used similar comparison groups in a study evaluating psyllium and GF flours in place of wheat flour to create a GFB product. No statistical differences in preference between groups were detected indicating that the developed products may be acceptable to those individuals with or without GI.

When comparing overall acceptance of the commercial product to the two developed GFB containing Montina ${ }^{\mathrm{TM}}$ or amaranth, significant differences were observed $(\mathrm{p}<0.001)$. Across both participant groups $(\mathrm{N}=222)$, the commercial GFB was significantly preferred over either developed bread and the Montina ${ }^{\mathrm{TM}}$-based bread was significantly preferred over the amaranth-based bread (Table 3). Likewise, the commercial bread product received statistically higher scores than either developed bread in all sensory attributes evaluated. The Montina $^{\mathrm{TM}_{-}}$and amaranth-based breads were acceptable products with means $>5.5$ out of 9 for all categories of evaluation (Table 3). The mean scores associated with likelihood of buying and comparison to similar gluten-free products on the market between the two developed breads were "neutral/no preference" (mean of 3.0 and 3.1 out of 5, respectively) for Montina ${ }^{\mathrm{TM}}$ and "somewhat unlikely/ prefer less" (mean of 2.8 out of 5, for both categories) for amaranth. Since sensory ratings and acceptance were lower than expected for both developed GFB, the lean bread recipe may need further modifications if these flours are to be used for in-home preparation of GFB. 
Table 3. Sensory analysis of developed gluten-free breads as compared to a commercially-marketed gluten-free bread as evaluated by gluten-free and non-restricted diet consumers

\begin{tabular}{lllllll}
\hline & Amaranth & \multicolumn{3}{c}{ Montina } & \multicolumn{3}{c}{ Commercial } \\
\cline { 2 - 7 } & Mean & S.D. & Mean & S.D. & Mean & S.D. \\
\hline Appearance & 6.9 & \pm 1.7 & 6.9 & \pm 1.6 & 7.8 & \pm 1.0 \\
Tenderness & 6.8 & \pm 1.9 & 7.2 & \pm 1.5 & 7.3 & \pm 1.4 \\
Texture & 6.5 & \pm 1.9 & 6.8 & \pm 1.6 & 7.4 & \pm 1.2 \\
Taste & 5.6 & \pm 2.1 & 6.2 & \pm 1.8 & 7.4 & \pm 1.4 \\
Overall Acceptance & 5.9 & \pm 2.0 & 6.3 & \pm 1.6 & 7.4 & \pm 1.3 \\
$\begin{array}{l}\text { Purchasing Potential } \\
\begin{array}{l}\text { Compared to other } \\
\text { gluten-free breads on the }\end{array}\end{array}$ & 2.8 & \pm 1.4 & 3 & \pm 1.3 & 3.8 & \pm 1.3 \\
market & & \pm 1.1 & 3.1 & \pm 1.0 & 3.7 & \pm 1.1
\end{tabular}

"Survey question: "Compared to similar gluten-free products on the market, how would you rate this product?"

Since the commercial GFB contained a higher sugar and fat content, the preference for this product may be the result of these two ingredients. For example, according to Schoenlechner, Mandala, Kiskini, Kostaropoulos, and Berghofer (2010), increasing the fat content in a GF amaranth bread to $2 \%$ decreased the bitter and moldy taste of amaranth and improved sensory evaluation and acceptance ratings. Although experimental research on the sensory qualities of Montina ${ }^{\mathrm{TM}}$-based bread products is lacking, incorporation of both sugar and fat into either of the developed GFB products would be expected to improve sensory evaluation scores.

\subsection{Objective Evaluation}

Objective testing results indicate no significant difference $(\mathrm{p}>0.05)$ in hardness/tenderness among breads (Figure 1). Thus, although there were differences in sensory preference and acceptability among the commercial and developed breads, these differences were not likely attributed to the textural quality of the bread. This could be attributed to the fact that most GFB includes a hydrocolloid in the product formulation or recipe for the purpose of imparting textural characteristics similar to gluten and improving the loaf quality by reducing crumb hardness (Crockett, Ie, \& Vodovotz, 2011). In this study, both developed breads contained guar gum as the hydrocolloid. Since no significant differences were detected between hardness/tenderness attributes, results indicate an adequate amount of hydrocolloid in the recipe formula.

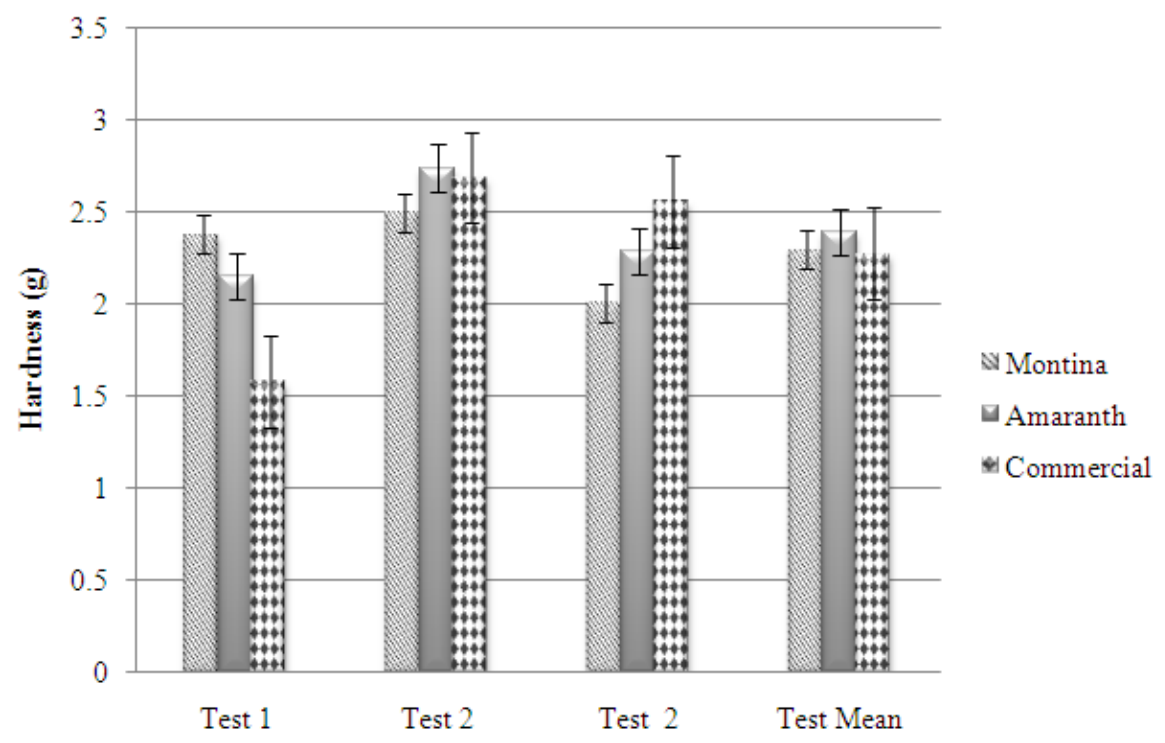

Figure 1.Tenderness of developed gluten-free breads compared to a commercially-marketed gluten-free bread.

Bars depict results of triplicate testing and the mean value of tests combined 
Since bread tenderness would be influenced by the rise of the bread, the density of each bread was assessed by visually comparing cell size of bread slices (Figure 2). The GFB containing amaranth exhibited a compact cell structure and a dip in the top surface where the bread collapsed while baking. These results suggest that ingredient proportions need further adjustment. The Montina ${ }^{\text {TM}}$-based bread exhibited an even texture and minimal cell compaction at the base of the bread. In comparison, the commercial product had the largest and most consistent cell size throughout the slice.

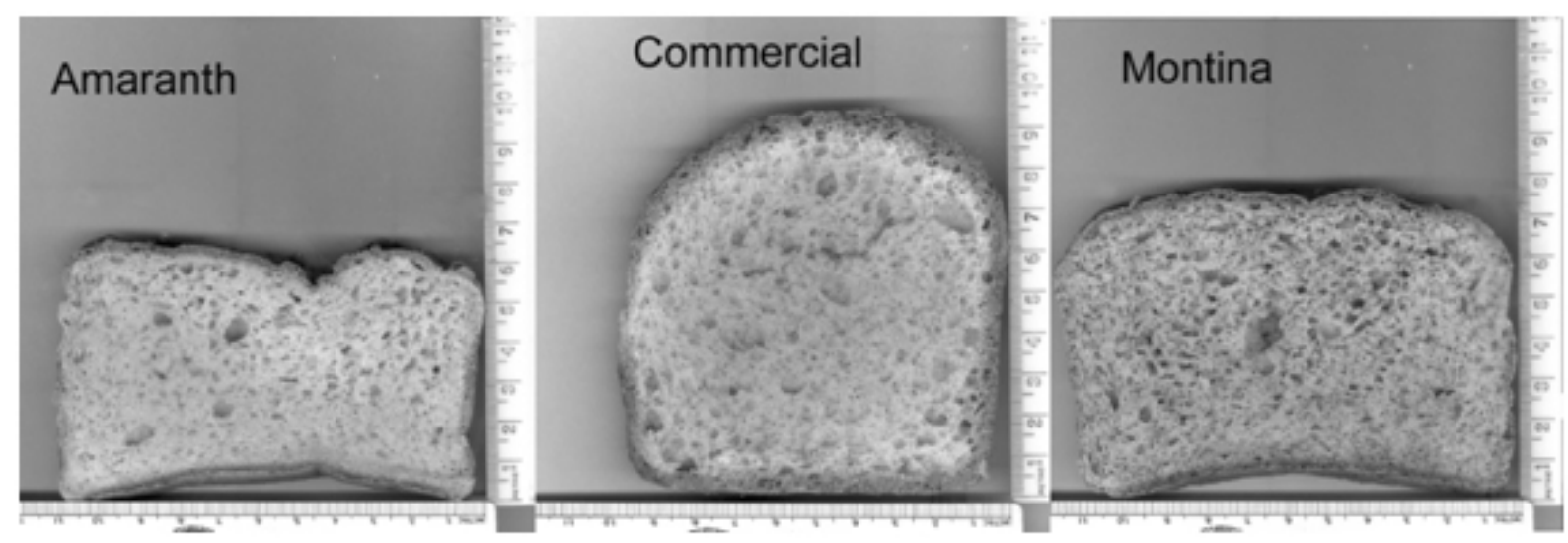

Figure 2. Cell size and density measurements of developed gluten-free breads compared to a commercially-marketed gluten-free bread

Not only was the texture of each bread visually different, but the color of the products also varied. The amaranth-based bread appeared most like the commercial bread despite a slight yellow tint which was also noticeable in the raw amaranth flour. The Montina ${ }^{\mathrm{TM}}$-based bread contained black particles throughout which was similar to the flour itself, exhibiting a multi-grain appearance. The commercial GFB product was similar in color to commercial multi-grain breads which contain bran particles due to the inclusion of the whole grain including the bran and germ; however, the dark particles were not as pronounced in color as the bread developed with Montina ${ }^{\mathrm{TM}}$. If a consumer preferred white bread, then the amaranth-based bread may be more appealing, whereas if consumer preference was for whole grain-type breads, then the Montina ${ }^{\mathrm{TM}}$-based bread may be more visually appealing.

Based on results of the study, considerations for future research include adjusting starch level and/or water content along with adjusting the sugar and fat content. Overall, the GFB developed with Montina ${ }^{\mathrm{TM}}$ exhibited a good rise, acceptable cell size, and acceptable texture. However, modifications such as those mentioned above should be made to improve sensory acceptability.

Amaranth which is known for its nutty flavor and unique texture has a low level of amylase starch, and as such, it often requires significant modifications of the base recipe when used in GFB. Current literature suggests replacing the original starch with up to $10 \%$ amaranth so as not to affect sensory qualities in a baked product (Arendt et al., 2009; Arendt \& Moore, 2006). In this study, amaranth was substituted at $20 \%$ of the total flour based on acceptability results of pilot test; however, this could explain the lower volume observed. According to Schoenlechner et al. (2010), adjusting the water content in amaranth-based breads has a significant influence on bread quality. Thus, increasing the water content would be expected to enhance starch gelatinization and hydration of the proteins resulting in a softer, less gummy bread with improved cell size and bread volume. For this reason, additional research is needed to determine if decreasing the amount of amaranth flour or increasing the recipe's water content may produce a GFB with sensory qualities more comparable to commercial GFB.

\section{Conclusion}

\subsection{Limitations}

Although a commercial GFB product was used as the comparison sample in establishing consumer expectations for sensory and quality attributes of GFB, it also may have been a limitation of the study. The commercial GFB was not a lean bread, and thus it contained added fat and sugar which may have influenced consumer preference. In future studies, it may be more advantageous to compare the Montina ${ }^{\mathrm{TM}}$ - and amaranth-based breads to the original lean bread recipe which contained only rice, potato, tapioca, and soy starches instead of to a non-lean 
commercial product. Another potential limitation of the study is the higher proportion of college-age participants which may limit the ability to generalize to all age groups within the $\mathrm{CD}$ and GI populations.

\subsection{Recommendations}

Developing an acceptable nutrient-dense GFB is possible, yet challenging as reported in this and other research studies. Additional research is needed to assist in the development of consumer-friendly GF products and in the development of GFB recipes for persons with CD that are interested in in-home preparation of GFB with similar sensory qualities to commercial GFB. The later type of research and development is critical in promoting dietary compliance among CD and GI individuals especially among those who commonly serve GF products and meals in the home to family members with non-restricted diets. For example, it has been shown that when the entire family eats GF, it is less difficult to follow a GF diet (Garcia-Manzanares \& Lucendo, 2011). Recommendations for future testing and development of amaranth-and Montina ${ }^{\mathrm{TM}}$-based breads include modifying the flour ratios and/or adding sugar, fat, and water into the recipe for improving the palatability of the bread and making it more comparable to commercial GFB. Registered dietitians can use this information to counsel clients with CD or GI by assisting the client with advice on preparing GFB in the home especially in regions of the country where the variety of GF products is limited.

\section{Acknowledgements}

The authorswould like to acknowledge the University of Central Missouri for financial support.

\section{References}

Abdel-Aal, E. M. (2009). Functionality of starches and hydrocolloids in gluten-free foods. In E. Gallagher (Ed.), Gluten-Free Food Science and Technology (pp. 200-224). http://dx.doi.org/10.1002/9781444316209.ch11

Alvarez-Jubete, L., Arendt, E. K., \& Gallagher, E. (2009). Nutritive value and chemical composition of pseudocereals as gluten-free ingredients. International Journal of Food Sciences and Nutrition, 60(S4), 240-257. http://dx.doi.org/10.1080/09637480902950597

Anton, A. A., \& Artfield, S. D. (2008). Hydrocolloids in gluten-free breads: a review. International Journal of Food Sciences and Nutrition, 59, 11-23. http://dx.doi.org/10.1080/09637480701625630

Araújo, H. M., \& Araújo, W. M. (2011). Coeliac disease. Following the diet and eating habits of participating individuals in the Federal District of Brazil. Appetite, 57, 105-109. http://dx.doi.org/10.1016/j.appet.2011.04.007

Arendt, E. K., \& Moore, M. M. (2006). Gluten-free cereal-based products. In Y. H. Hui (Ed.), Bakery Products: Science and Technology (pp. 471-495). http://dx.doi.org/10.1002/9780470277553.ch27

Arendt, E. K., Renzetti, S., \& Bello, F. D. (2009). Doughs microstructure and textural aspects of gluten-free yeast bread and biscuits. In E. Gallagher (Ed.), Gluten-Free Food Science and Technology (pp. 107-129). http://dx.doi.org/10.1002/9781444316209.ch8

Arnold Bread. (2012). Retrieved from http://www.arnoldbread.com/nutrition/nutrition-label

Black, J. L., \& Orfila, C. (2011). Impact of ceoliac disease on dietary habits and quality of life. Journal of Human Nutrition and Dietetics, 24, 582-587. http://dx.doi.org/10.1111/j.1365-277X.2011.01170.x

Coppedge, R. J. (2008). Gluten-free baking with the Culinary Institute of America. Avon, MA: Adamsmedia.

Crockett, R., Ie, P., \&Vodovotz, Y. (2011). How do xanthan and hydroxypropyl methylcellulose individually affect the physicochemical properties in a model gluten-free dough? Journal of Food Science, 76(3), E274-82.http://dx.doi.org/10.1111/j.1750-3841.2011.02088.x

de la Barca, A. M., Rojas-Martinex, M. E., Islas-Ruboi, A. R., \& Cabrera-Chávez, F. (2010). Gluten-free breads and cookies of raw and popped amaranth flours with attractive technological and nutritional qualities. Plant Foods for Human Nutrition, 65, 241-246. http://dx.doi.org/10.1007/s11130-010-0187-z

Dietary Supplement Fact Sheet: Vitamin $\mathrm{B}_{12}$ (2011). In Office of Dietary Supplements National Institutes of Health.Retrieved fromhttp://ods.od.nih.gov/factsheets/VitaminB12-HealthProfessional/\#h2

Di Sabatino, A., \& Corazza, G. R. (2012). Nonceliac gluten sensitivity: Sense or sensibility? Annals of Internal Medicine, 156(4), 309-11. http://dx.doi.org/10.7326/0003-4819-156-4-201202210-00010

Do You Have Celiac Disease? (n.d.). In Celiac Sprue Association: Celiacs Helping Celiacs. Retrieved from http://www.csaceliacs.info/symptoms_of_celiac_disease.jsp 
Folate Fact Sheet. (2004). In Ohio State University Extension Fact Sheet. Retrieved from http://ohioline.osu.edu/hyg-fact/5000/5553.html

Garcia-Manzanares, A., \& Lucendo, A. J. (2011). Nutritional and dietary aspects of celiac disease.Nutrition in Clinical Practice,26, 163-173. http://dx.doi.org/10.1177/0884533611399773

Gilbert, A., Espadaler, M., Canela, M.A., Sánchez, A., Vaqué, C., \& Rafecas, M. (2006). Consumption of gluten-free products: Should the threshold value for trace amounts of gluten be at 20, 100, or 200 p.p.m.? European Journal of Gastroenterologoy \& Hepatology, 18 , 1187-1195.http://dx.doi.org/10.1097/01.meg.0000236884.21343.e4

Green, P. H., \& Cellier, C. (2007).Celiac disease medical progress. The New England Journal of Medicine, 357, 1731-1743. http://dx.doi.org/10.1056/NEJMra071600

Gruss, T. (n.d.) In Gluten-free flour and starch glossary. Retrieved from http://glutenfreecooking.about.com/od/glutenfreeingredients/tp/20-Gluten-Free-Flours.htm

Hallert, C., Grant, C., Grehn, S., Grännö, C., Hultén, S., Midhagens, ...Valdimarsson, T. (2002). Evidence of poor vitamin status in coeliac patients on a gluten-free diet for 10 years.Alimentary Pharmacology \& Therapeutics, 16, 1333-1339. http://dx.doi.org/10.1046/j.1365-2036.2002.01283.x

Hillson, B. (Dec/Jan 2010). Gluten-free flour power. In Living without. Retrieved from $\mathrm{http} / / /$ www.livingwithout.com/issues/4_1/gluten_free_flour-1073-1.html

Hoye, C., \& Ross, C. (2011). Total phenolic content, consumer acceptance, and instrumental analysis of bread made with grape seed flour. Journal of Food Science, 76(7), S428-436. http://dx.doi.org/10.1111/j.1750-3841.2011.02324.x

Kinsey, L., Burden, S. T., \& Bannerman, E. (2008). A dietary survey to determine if patients with coeliac disease are meeting current healthy eating guidelines and how their diet compares to that of the British general population. European Journal of Clinical Nutrition, 62, 1333-1342. http://dx.doi.org/10.1038/sj.ejcn.1602856

Krupa, U., Rosell, C. M., Sadowska, J., \& Soral-Smietana, M. (2010). Bean starch as ingredient for gluten-free bread. Journal of Food Processing and Preservation, 34, 501-581. http://dx.doi.org/10.1111/j.1745-4549.2009.00366.x

Lamontagne, P., West, G. E., \& Galibois, I. (2001). Quebecers with celiac disease: Analysis of dietary problems. Canadian Journal of Dietetic Practice and Research, 62, 175-181.

Larmond, E. (1991). Laboratory methods for sensory analysis of food. Ottawa, Canada: Agriculture Canada.

Latimer, G. W. (2012). Official Methods of Analysis of the Association of Official Analytical Chemists (AOAC) International (19th ed). Gaithersburg, MD: AOAC International.

Lawless, H. T., \& Heymann, H. (2010). Sensory evaluation of food (pp. 325-347), Food Science Text Series.http://dx.doi.org/10.1007/978-1-4419-6488-5_14

Lee, A. R., Ng, D. L., Zivin, J., \& Green, P. H. (2007). Economic burden of a gluten-free diet. Journal of Human Nutrition and Dietetics, 20, 423-430. http://dx.doi.org/10.1111/j.1365-277X.2007.00763.x

McWilliams, M. (2008). Foods Experimental Perspectives(6th ed). Upper Saddle River, NJ: Pearson Prentice Hall.

Mezaize, S., Chevallier, S., Le Bail, A., \& De Lamballerie, M. (2009). Optimization of gluten-free formulations for French-style breads. Journal of Food Science, 74(3), E140-E146. http://dx.doi.org/10.1111/j.1750-3841.2009.01096.x

Mission Mountain Food Enterprise Center (n.d.). Montina Pure Ingredient Nutrition.

Nature's Own. (2012). Retrieved from http://naturesownbread.com/assets/PDFs/products/100WW20-24.pdf

Pagano, A.E. (2006). Whole grains and the gluten-free diet. Practical Gastroenterology, 29, 66-78.

Sands, D. (2010, October). Discovery, innovation, production - better foods. In B. Eyl (Chair), Changing the World for Celiacs. Symposium conducted at the meeting of the Celiac Sprue Association, Kansas City, MO.

Saturni, L., Ferretti, G., \& Bacchetti, T. (2010). The gluten-free diet: Safety and nutritional quality. Nutrients, 2, 16-34. http://dx.doi.org/10.3390/nu2010016 
Schober, T. J., Bean, S. R., \& Boyle, D. L. (2007). Gluten-free sorghum bread improved by sourdough fermentation: Biochemical, rheological, and microstructural background. Journal of Agricultural and Food Chemistry, 55, 5137-5146. http://dx.doi.org/10.1021/jf0704155

Schoenlechner, R., Mandala, I., Kiskini, A., Kostaropoulos, A., \& Berghofer, E. (2010). Effect of water, albumen and fat on the quality of gluten-free bread containing amaranth. International Journal of Food Science \& Technology, 45, 661-669. http://dx.doi.org/10.1111/j.1365-2621.2009.02154.x

See, J., \& Murray, J. A. (2006). Gluten-free diet: the medical and nutrition management of celiac disease. Nutrition in Clinical Practice, 21, 1-15. http://dx.doi.org/10.1177/011542650602100101

Shah, S., \& Leffler, D. (2010). Celiac disease: an underappreciated issue in women's health. Womens Health, 6 , 753-766. http://dx.doi.org/10.2217/whe.10.57

Singh, J., \& Whelan, K. (2011). Limited availability and higher cost of gluten-free foods. Journal of Human Nutrition and Dietetics, 24, 479-86. http://dx.doi.org/10.1111/j.1365-277X.2011.01160.x

Stone, H., \& Sidel, J. L. (2004). Sensory evaluation practices (3rd ed). Redwood City, CA: Elsevier Academic Press.

Thompson, T. (2000). Folate, iron, and dietary fiber contents of the gluten-free diet. Journal of the American Dietetic Association, 100, 1389-1396. http://dx.doi.org/10.1016/S0002-8223(00)00386-2

Thompson, T. (2009). The nutritional quality of gluten-free foods. In E. Gallagher (Ed.), Gluten-Free Food Science and Technology (pp. 42-51). http://dx.doi.org/10.1002/9781444316209.ch4

Thompson, T., Dennis, M., Higgins, L. A., Lee, A. R., \& Sharrett, M. K. (2005). Gluten-free diet survey: are Americans with coeliac disease consuming recommended amounts of fibre, iron, calcium and grain foods? Journal of Human Nutrition and Dietetics, 163-169. http://dx.doi.org/10.1111/j.1365-277X.2005.00607.x

U.S. Department of Agriculture, Agricultural Research Service. (2010). In USDA National Nutrient Database for Standard Reference, Release 24. Retrieved from http://www.ars.usda.gov/ba/bhnrc/ndl

What is gluten intolerance (n.d.). In Gluten Intolerance Info. net. Retrieved from http://www.glutenintoleranceinfo.net/

Yano, H. (2010). Improvements in the bread-making quality of gluten-free rice batter by glutathione. Journal of Agricultural and Food Chemistry, 58, 7949-7954. http://dx.doi.org/10.1021/jf1003946

Zandonadi, R. P., Botlho, R. B., \& Araujo, W. M. (2009). Psyllium as a substitute for gluten in bread. Journal of the American Dietetic Association, 109, 1781-1784. http://dx.doi.org/10.1016/j.jada.2009.07.032

\section{Copyrights}

Copyright for this article is retained by the author(s), with first publication rights granted to the journal.

This is an open-access article distributed under the terms and conditions of the Creative Commons Attribution license (http://creativecommons.org/licenses/by/3.0/). 